\title{
Application of oblique nerve coaptation in autologous nerve transplantation
}

\author{
Lian Ouyang ${ }^{1 \#}$, Fan Zhang ${ }^{2 \#}$, Junjian Liu ${ }^{2}$, Shumin Cui ${ }^{3}$, Keying Chen ${ }^{1}$, Jianguang Wang ${ }^{2}$, Lihui Zhou ${ }^{1}$ \\ ${ }^{1}$ Department of Orthopaedic Surgery, Xiangshan First People's Hospital, Ningbo, China; ${ }^{2}$ Department of Orthopedics, Shanghai Tenth People's \\ Hospital, Tongji University School of Medicine, Shanghai, China; ${ }^{3}$ Department of Obstetrics and Gynecology, Xiangshan Maternal and Child Care \\ Service Center, Ningbo, China \\ Contributions: (I) Conception and design: L Ouyang, F Zhang; (II) Administrative support: L Zhou, J Wang; (III) Provision of study materials \\ or patients: J Liu, L Zhou; (IV) Collection and assembly of data: S Cui, K Chen; (V) Data analysis and interpretation: L Ouyang, F Zhang; (VI) \\ Manuscript writing: All authors; (VII) Final approval of manuscript: All authors. \\ \#These authors contributed equally to this work. \\ Correspondence to: Lihui Zhou. Department of Orthopaedic Surgery, Xiangshan First People’s Hospital, Ningbo, China. Email: lihui_chow@163.com; \\ Jianguang Wang. Department of Orthopedics, Shanghai Tenth People's Hospital, Tongji University School of Medicine, Shanghai, China. \\ Email: jianguangwang@163.com.
}

Background: Autologous nerve transplantation has become the gold standard for other nerve repair methods. But conventional epineurial sutures is prone to misaligned sutures, erroneous axonal growth, and unsatisfactory repair. Finding a new, more effective nerve coaptation method to improve the efficacy of peripheral nerve repair remains an urgent clinical challenge. In this study, the repair efficacies of oblique nerve coaptations for sciatic nerve injury at various angles were observed, providing a theoretical foundation for further clinical applications.

Methods: Sixty-four Sprague-Dawley rats were randomized into four groups of 16. The autologous nerve transplantation model was established by severing and rejoining in situ a $10-\mathrm{mm}$ segment of the sciatic nerve trunk at the angle of $30^{\circ}$ (group A), $45^{\circ}$ (group B), $60^{\circ}$ (group C), or $90^{\circ}$ (group D). Sciatic function index (SFI) measurement, measurement of the recovery rate of the wet weight of the triceps surae, electrophysiological examination of nerves, histological examinations, and image analysis were carried out 12 weeks after surgery.

Results: The SFI, the recovery rate of the wet weight of the triceps surae, the electrophysiological function of nerves, histological examinations, and image analysis 12 weeks after surgery indicated that all indices of groups A and B were significantly better than those of groups $\mathrm{C}$ and $\mathrm{D}(\mathrm{P}<0.05)$. There was no significant difference between groups $\mathrm{A}$ and $\mathrm{B}$ or between groups $\mathrm{C}$ and $\mathrm{D}(\mathrm{P}>0.05)$, although group $\mathrm{C}$ exhibited a trend of better recovery than group D.

Conclusions: Oblique nerve coaptation at $30-45^{\circ}$ in autologous nerve transplantation may significantly enhance nerve regeneration.

Keywords: Nerve damage; nerve repair; oblique nerve coaptation

Submitted Jul 19, 2020. Accepted for publication Oct 19, 2020.

doi: $10.21037 / \mathrm{atm}-20-6526$

View this article at: http://dx.doi.org/10.21037/atm-20-6526 


\section{Introduction}

Peripheral nerve injury often leads to significant functional impairment and poses a tremendous burden on individuals and society. Despite modern diagnostic procedures and advanced microsurgical techniques, The repairing of peripheral nerve damage has long been a difficult challenge clinically, and currently the most common clinical treatment is autologous nerve transplantation. Clinically, conventional epineurial sutures are performed by coaptating nerve stump endings that were transected perpendicularly to the longitudinal axis of the nerve trunk. However, since the nerve trunk is long and cylindrical, its perpendicular section is round, making it difficult to align the two ends correctly during epineurial suture repair. Thus, the procedure is prone to misaligned sutures, erroneous axonal growth, and unsatisfactory repair.

During conventional autologous nerve transplantation, the nerve endings are transected at a right angle to the longitudinal axis before coaptation. In 1999, Kayikçioğlu et al. proposed a new method for coaptation of nerve endings (1). When the nerve endings are coapted at $90^{\circ}$, the area of the coaptation interface is $\pi^{*}(\mathrm{r} 1) *(\mathrm{r} 1)$; with coaptation at $30^{\circ}$, the area of the interface is $\pi^{*}(\mathrm{r} 1) *(\mathrm{r} 2)$, where $\mathrm{r} 2=2 \mathrm{r} 1$. Therefore, the area of the coaptation interface of a coaptation at $30^{\circ}$ is twice that of a coaptation at $90^{\circ}$, and the expanded interface allows more space for axon growth. Yan et al. performed similar experiments and compared nerve regeneration after the sciatic nerves of rats were severed at various angles before coaptation. Their results showed that compared with transverse nerve coaptation, oblique nerve coaptation at acute angles resulted in significantly better restoration of nerve function and more regenerated nerve fibers (2). However, because there are two coaptation sites, the effectiveness of nerve regeneration has not been satisfactory.

In this paper, we studied autogenous nerve transplantation of oblique suture, while Kayikçioğlu et al. studied in situ oblique suture after peripheral nerve injury, and our study got similar results (1). The purpose of this study was to verify whether oblique nerve coaptation at acute angles can achieve similar effects in nerve transplantation and to provide a theoretical foundation for further clinical applications. We present the following article in accordance with the ARRIVE reporting checklist (available at http://dx.doi.org/10.21037/atm-20-6526).

\section{Methods}

\section{Experimental animals and surgical methods}

Sixty-four healthy adult male Sprague-Dawley rats weighing 250-300 g (8-week-old) were provided by the Experimental Animal Center at Shanghai Sixth People's Hospital. They were kept under the standard conditions $\left(25 \pm 2{ }^{\circ} \mathrm{C}\right.$, humidity: $55 \% \pm 5 \%, 12: 12 \mathrm{~h} \mathrm{light/dark),} \mathrm{and} \mathrm{had} \mathrm{free} \mathrm{access} \mathrm{to} \mathrm{the}$ standard laboratory diet and water. The rats was randomized into groups A, B, C, and D with 16 in each group. The right side of each rat was the experimental side, while the left side was the normal control side. Experiments were performed under a project license (2019[15]) granted by institutional ethics committee of Xiangshan First People's Hospital, in compliance with institutional guidelines for the care and use of animals. After anesthesia via intraperitoneal injection of ketamine, a longitudinal incision was made at the dorsal lateral side of the right thigh of the rat, and the sciatic nerve was exposed through the opening between muscles. A polyethylene board with an angle of $30^{\circ}, 45^{\circ}, 60^{\circ}$, or $90^{\circ}$ was made to guide nerve transection. A nerve trunk segment approximately $10 \mathrm{~mm}$ in length was transected in the midsection of the sciatic nerve at an angle guided by the board, followed by in situ coaptation: $30^{\circ}$ for group A (Figure $1 A$ ), $45^{\circ}$ for group B (Figure $1 B$ ), $60^{\circ}$ for group C (Figure 1C), and $90^{\circ}$ for group D (Figure 1D). The rats were examined 12 weeks after surgery.

\section{Examination of experimental samples}

\section{Measurement of sciatic function index (SFI)}

A container was custom made to record the footprints of the rats and lined at the bottom with a piece of white paper with the same dimensions. The rat was led to walk into the container after its hind feet were dipped in carbon ink. Four to five clear prints of each hind foot were recorded. The length of the footprint, the toe spread, and the intermediate toe spread were measured for feet on the experimental side (E) and the normal control side (N). The SFI was calculated with the aforementioned parameters and the following formula:

$$
\begin{aligned}
& \mathrm{SFI}=-38.3(\mathrm{EPL}-\mathrm{NPL}) / \mathrm{NPL}+109.5(\mathrm{ETS}-\mathrm{NTS}) / \\
& \mathrm{NTS}+13.3(\mathrm{EIT}-\mathrm{NIT}) / \mathrm{NIT}-8.8
\end{aligned}
$$

where EPL is the experimental-side print length; NPL is the normal-side print length; ETS is the experimental-side 

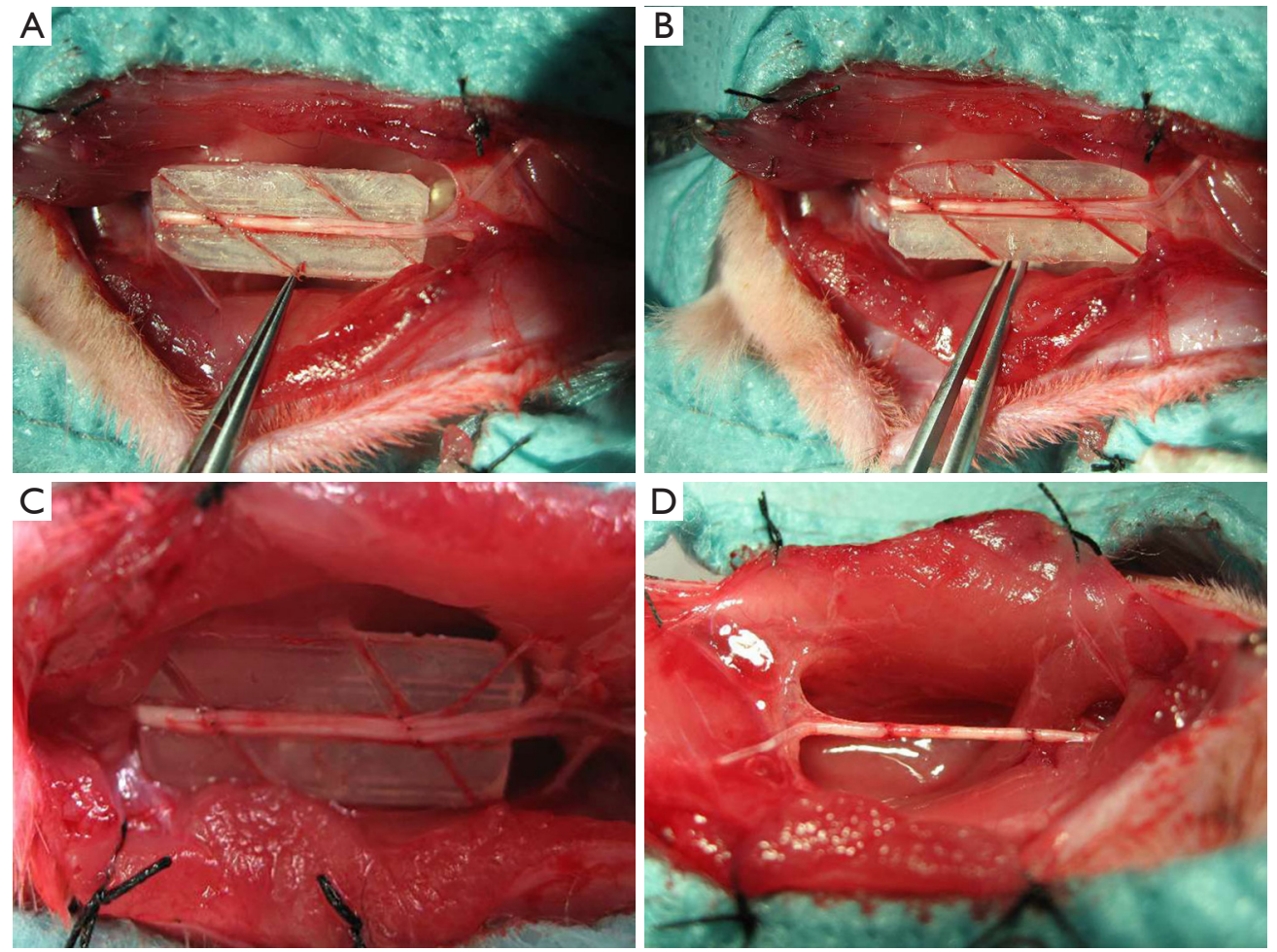

Figure 1 Oblique nerve coaptation of rat sciatic nerves. (A) Coaptation at $30^{\circ}$. (B) Coaptation at $45^{\circ}$. (C) Coaptation at $60^{\circ}$. (D) Coaptation at $90^{\circ}$.

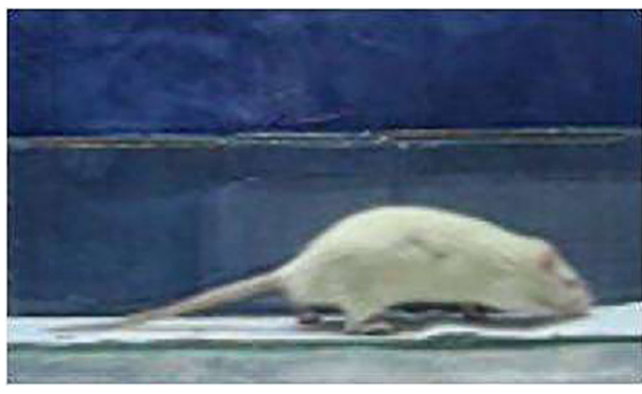

Figure 2 Measurement of the rat sciatic function index.

toe spread; NTS is the normal-side toe spread; EIT is the experimental-side intermediate toe spread; and NIT is the normal-side intermediate toe spread. The SFI value for a normal rat is 0 , and that for a rat with a completely severed sciatic nerve is -100 (Figure 2).

\section{Measurement of the wet weight of the triceps surae}

The bilateral triceps surae muscles were completely removed 12 weeks after surgery. Blood was removed by gentle blotting of the surface, and the wet weight of the muscles was measured on a scale. The muscle recovery rate was obtained by comparing the muscles from the two sides (experimental, normal).

\section{Electrophysiological examinations of nerves}

Electrophysiological examination was performed 12 weeks after surgery with an SDR-4 oscilloscope. The stimulus was a 0.01-to-0.02-ms square electric pulse with an intensity of $2-5 \mathrm{~V}$. Bipolar-coated electrodes were applied as stimulating electrodes on the proximal and distal sides of the coapted segment, and a needle electrode was inserted into the center of the midsection of gastrocnemius muscle of the rat to record the nerve conduction velocity $(\mathrm{NCV})$ of the sciatic nerve and amplitude (AMP) of the compound action potential.

\section{Histological examinations}

A rat nerve specimen $2 \mathrm{~mm}$ distal to the distal coaptation site of the transplantation was collected, fixed in $4 \%$ glutaraldehyde for at least 24 hours, and postfixed with $1 \%$ osmium acid. Oriented embedding was performed using epoxy resin, and ultrathin sections were stained with uranyl 


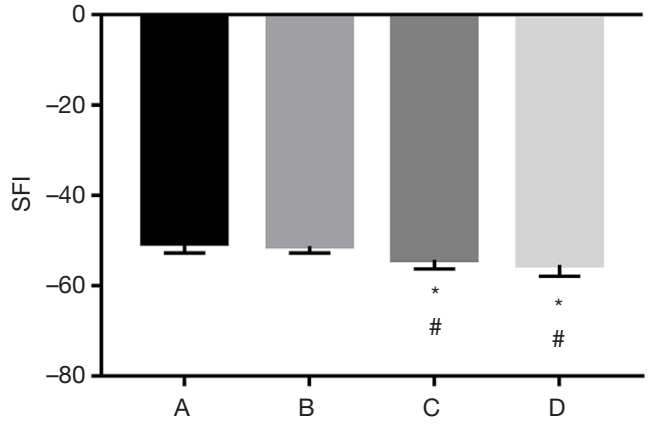

Figure 3 SFI values of rats 12 weeks after surgery in each group $(\mathrm{n}=16, \bar{x} \pm s) .{ }^{*}, \mathrm{P}<0.05$ vs. group $\mathrm{A} ;{ }^{\#}, \mathrm{P}<0.05$ vs. group B. SFI, Sciatic function index.

acetate and lead citrate. Axon regeneration and myelin sheath formation were examined under a transmission electron microscope.

\section{Statistical analysis}

SPSS 10.0 was used to perform one-way analysis of variance (ANOVA) and the Student-Newman-Keuls test for pairwise comparisons of the means of various samples $(\alpha=0.05)$.

\section{Results}

\section{SFI evaluation}

Rats in group A showed the lowest SFI values 12 weeks after surgery, followed by group B. The differences between groups $\mathrm{A}$ or $\mathrm{B}$ and $\mathrm{C}$ or $\mathrm{D}$ were significant $(\mathrm{P}<0.05)$, while there was no significant difference between groups $\mathrm{A}$ and $\mathrm{B}$ or between groups $\mathrm{C}$ and $\mathrm{D}(\mathrm{P}>0.05)$ (Figure 3).

\section{Measurement of the recovery of the wet weight of the triceps surae}

The recovery rates of the wet weight of the triceps surae of rats in group A and B were significantly higher than those in group C and D 12 weeks after surgery $(\mathrm{P}<0.05)$. Although the difference between group $\mathrm{C}$ and $\mathrm{D}$ was nonsignificant ( $\mathrm{P}>0.05)$, and group $\mathrm{C}$ did show better recovery than group D (Figure 4).

\section{Electrophysiological examinations}

Action potentials were recorded distal to the distal

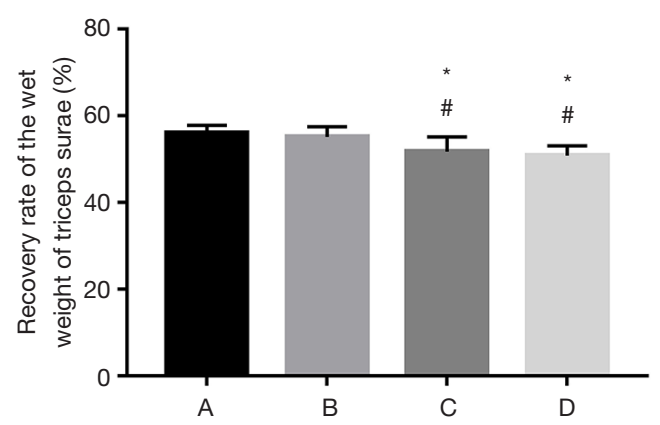

Figure 4 The recovery rate of the wet weight of triceps surae 12 weeks after surgery in each group $(\mathrm{n}=16, \%, \bar{x} \pm s)$. *, $\mathrm{P}<0.05$ vs. group $\mathrm{A} ;{ }^{\#}, \mathrm{P}<0.05$ vs. group $\mathrm{B}$.

coaptation site of rats in every group 12 weeks after surgery. The NCV and AMP of the compound action potentials in rats in groups $\mathrm{A}$ and $\mathrm{B}$ were higher than those in groups $\mathrm{C}$ and D. The action potentials of groups $\mathrm{A}$ and $\mathrm{B}$ were similar in shape, though group B had insignificantly lower amplitude and $\mathrm{NCV}(\mathrm{P}>0.05)$ (Figure 5).

\section{Histological examinations}

Transmission electron microscopy revealed high densities of regenerated axons that were evenly distributed in nerve specimens from groups A and B, and myelin sheaths formed by Schwann cells were observable surrounding the axons. There was no significant difference between groups A and $B$ in the number of nerves or the diameter of the axons $(\mathrm{P}>0.05)$. Specimens from group $\mathrm{D}$ had fewer regenerated nerve fibers, and the fibers were unevenly distributed. The axons were thin and irregular, with thin myelin sheaths. Specimens from group C showed more regenerated nerve fibers than those from group $\mathrm{D}$, but the difference was not significant $(\mathrm{P}>0.05)$ (Figures 6,7).

\section{Discussion}

Better nerve regeneration is achieved when more nerve fibers pass through the nerve coaptation site. Kayikçioğlu et al. and Yan et al. $(1,2)$ suggested that the number of regenerated nerve fibers is closely correlated with the area of the coaptation interface. When the nerve endings are coapted at $90^{\circ}$, the area of the coaptation interface is $\pi \mathrm{r} 12$; with coaptation at $30^{\circ}$, the area of the interface is $\varpi \mathrm{r} 1 \mathrm{r} 2$, where $\mathrm{r} 2=2 \mathrm{r} 1$. Therefore, the area of the coaptation interface of a coaptation at $30^{\circ}$ is twice that of a coaptation 

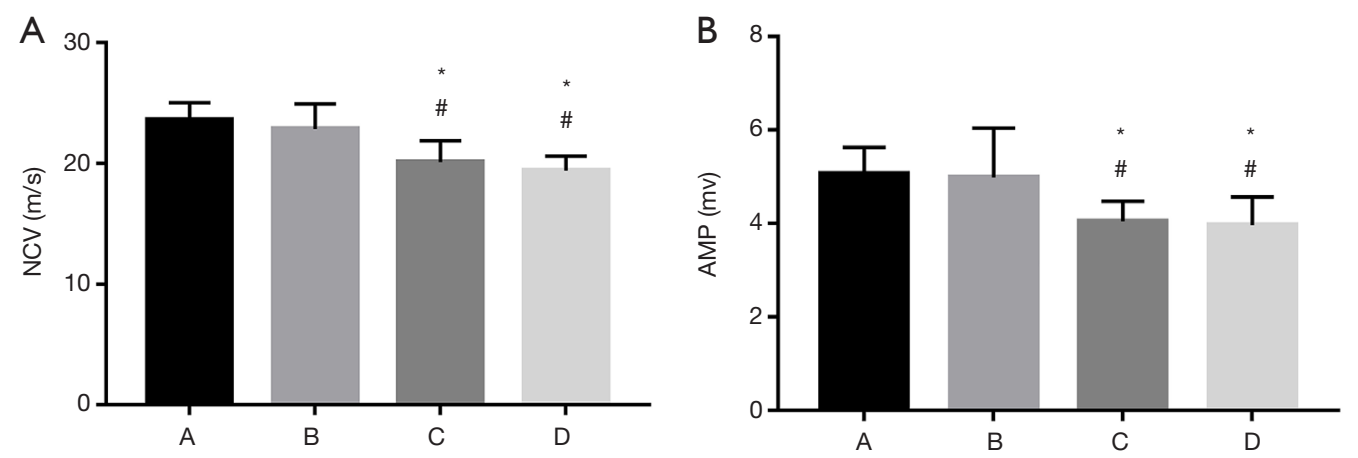

Figure 5 Electrophysiological measurements of each group 12 weeks after surgery $(\mathrm{n}=16, \bar{x} \pm s)$. (A) The NCV of the sciatic nerve. (B) The AMP of the compound action potential. *, $\mathrm{P}<0.05$ vs. group $\mathrm{A} ;{ }^{*}, \mathrm{P}<0.05$ vs. group $\mathrm{B}$. $\mathrm{NCV}$, nerve conduction velocity; AMP, amplitude.
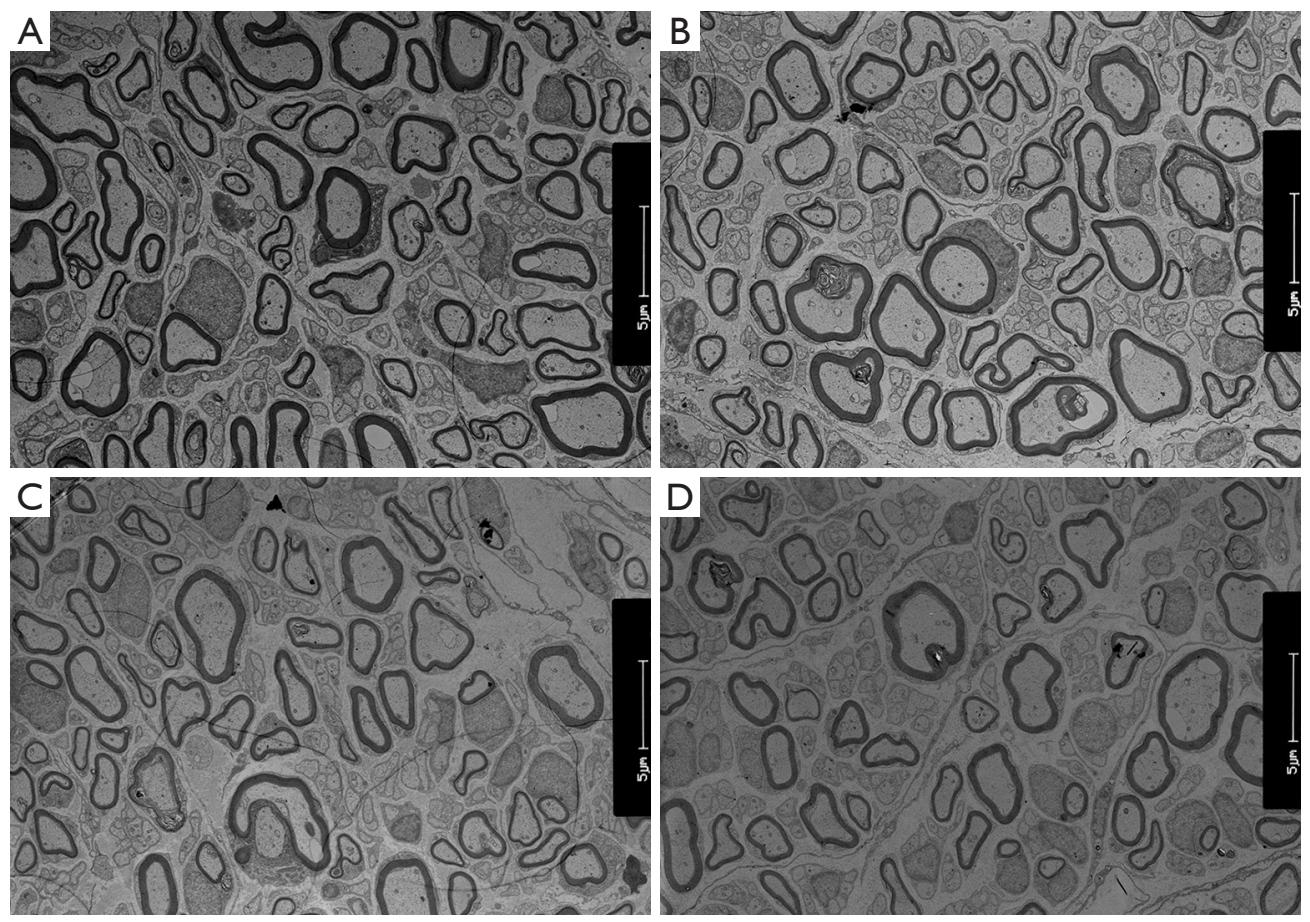

Figure 6 The regeneration of nerve fibers observed under a transmission electron microscope $(\times 2,000)$. (A) $30^{\circ}$-coaptation group; (B) $45^{\circ}$-coaptation group; (C) $60^{\circ}$-coaptation group; (D) $90^{\circ}$-coaptation group.

at $90^{\circ}$, and the expanded interface allows more space for axon growth. Galtrey et al. (3) reported that the extent of functional recovery after nerve damage was correlated with the direction of axon regeneration and the number of axon sprouts. The larger interface allows for the end distal to the degeneration site to exert greater inducing effects, leading to more axonal sprouting following injury and better recovery of nerve functions. The results from the current study also indicated that the SFI value, wet weight of the triceps surae, and neural electrophysiological performance were all superior in groups subjected to coaptation at $30^{\circ}$ or $45^{\circ}$ compared with the group that underwent coaptation at $90^{\circ}$. On the distal side of the distal coaptation site of the autologous transplantation, groups with coaptation at $30^{\circ}$ and $45^{\circ}$ also exhibited more regenerated fibers and greater axon diameters than the group with coaptation at $90^{\circ}$. There was no significant difference in these parameters between the groups with coaptation at $60^{\circ}$ and $90^{\circ}$. 

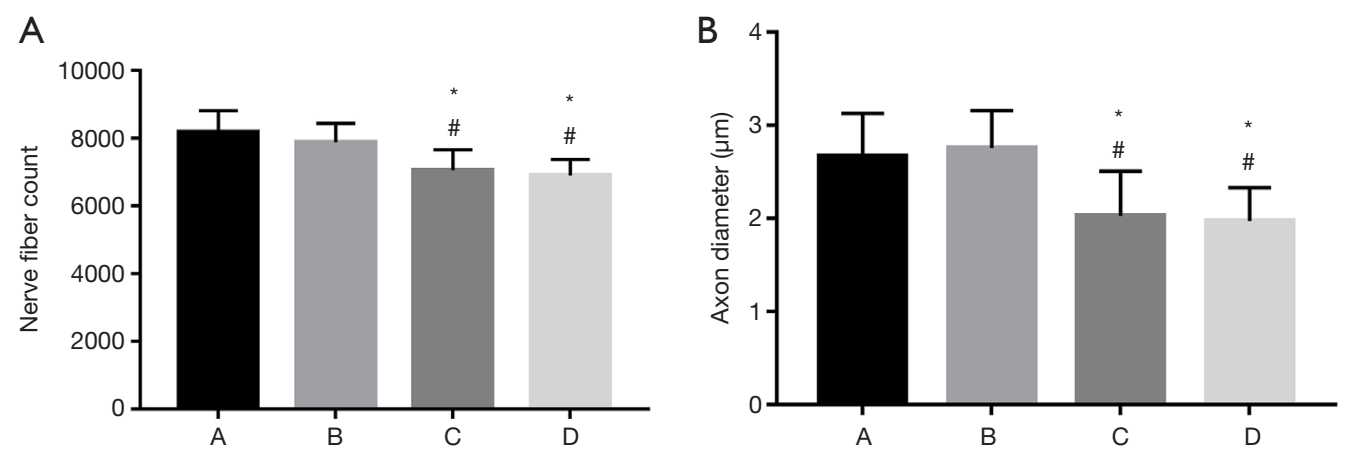

Figure 7 Image analysis of midsections of regenerated nerve fibers 12 weeks after surgery $(\mathrm{n}=16, \bar{x} \pm s)$. (A) The nerve fiber count. (B) The axon diameter. * $\mathrm{P}<0.05$ vs. group $\mathrm{A} ;{ }^{*}, \mathrm{P}<0.05$ vs. group $\mathrm{B}$.

Therefore, we consider the area of coaptation interface to be an important deciding factor in nerve regeneration, even when the regenerated nerve fibers have passed two coaptation sites. Many researchers (4-6) studying end-toside nerve coaptation also found that the regenerated nerves after oblique nerve coaptation are better in functional and histological tests than those after transverse coaptation.

Second, neuroma is a common complication following nerve coaptation and may affect the function of the repaired nerve (7). The presence of too many neuromas around the repaired nerve may reduce axonal sprouting and cause axon misdirection, hampering the recovery of nerve function (8). After coaptation at an acute angle, the axons can regenerate at different levels perpendicular to the axon axis, reducing mutual damage between axon sprouts and the formation of neuromas. Yan et al. (9) pointed out that the neuromas formed after transverse coaptation were all on the same level, while those formed after oblique nerve coaptation were on different levels and were fewer in number, leading to more axon sprouts.

Third, Bryan et al. (10) found significantly more Schwann cells around the nerve after oblique nerve coaptation than transverse coaptation, which may be due to the larger contact surface of the damaged nerve in oblique nerve coaptation. Schwann cells provide nutrients and other essential substances for nerve regeneration and are thus very important for axon growth. Schwann cells also provide the proper matrix for axon regeneration and serve as the main source of various neurotrophins, playing key roles in nerve regeneration (11).

Fourth, during oblique nerve coaptation, the longer uncut fibers on the proximal end may serve as the scaffold for shorter fibers to grow toward the distal end.
Fifth, oblique nerve coaptation can markedly reduce scar formation at the coaptation site. Yan et al. (5) suggested that the scars form a circular constriction around the nerve surface after transverse coaptation, increasing the pressure inside the nerve and limiting axon regeneration.

We conclude that oblique nerve coaptation not only can be used in direct nerve coaptation but can also produce superior results in autologous nerve transplantation. Therefore, it may warrant wider clinical application, but further investigation is needed to address the results.

\section{Acknowledgments}

Funding: None.

\section{Footnote}

Reporting Checklist: The authors have completed the ARRIVE reporting checklist. Available at http://dx.doi. org/10.21037/atm-20-6526

Data Sharing Statement: Available at http://dx.doi. org/10.21037/atm-20-6526

Conflicts of Interest: All authors have completed the ICMJE uniform disclosure form (available at http://dx.doi. org/10.21037/atm-20-6526). The authors have no conflicts of interest to declare.

Ethical Statement: The authors are accountable for all aspects of the work in ensuring that questions related to the accuracy or integrity of any part of the work are appropriately investigated and resolved. All animal 
experimental protocols were reviewed and approved by the ethics committee of Xiangshan First People's Hospital (2019[15]). Experiments were performed in compliance with institutional guidelines for the care and use of animals.

Open Access Statement: This is an Open Access article distributed in accordance with the Creative Commons Attribution-NonCommercial-NoDerivs 4.0 International License (CC BY-NC-ND 4.0), which permits the noncommercial replication and distribution of the article with the strict proviso that no changes or edits are made and the original work is properly cited (including links to both the formal publication through the relevant DOI and the license). See: https://creativecommons.org/licenses/by-nc-nd/4.0/.

\section{References}

1. Kayikçioğlu A, Karamürsel S, Ağaoğlu G, et al. A new epineural nerve repair technique: oblique nerve coaptation. Ann Plast Surg 1999;43:506-12.

2. Yan YH, Yan JG, Sanger JR, et al. Nerve repair at different angles of attachment: experiment in rats. J Reconstr Microsurg 2002;18:703-8.

3. Galtrey CM, Fawcett JW. Characterization of tests of functional recovery after median and ulnar nerve injury and repair in the rat forelimb. J Peripher Nerv Syst 2007;12:11-27.

4. Zhao Q, Dahlin LB, Kanje M, et al. Specificity of muscle

Cite this article as: Ouyang L, Zhang F, Liu J, Cui S, Chen K, Wang J, Zhou L. Application of oblique nerve coaptation in autologous nerve transplantation. Ann Transl Med 2020;8(20):1300. doi: 10.21037/atm-20-6526 reinnervation following repair of the transected sciatic nerve. A comparative study of different repair techniques in the rat. J Hand Surg Br 1992;17:257-61.

5. Yan JG, Matloub HS, Sanger JR, et al. A modified end-toside method for peripheral nerve repair: large epineurial window helicoid technique versus small epineurial window standard end-to-side technique. J Hand Surg Am 2002;27:484-92.

6. Kim BS, Choy WS, Chung MS, et al. Modified endto-side neurorrhaphy enhances axonal sprouting: a motor functional and morphological study. Orthopedics 2007;30:853-8.

7. Spanagel R, Hölter SM. Long-term alcohol selfadministration with repeated alcohol deprivation phases: an animal model of alcoholism? Alcohol Alcohol 1999;34:231-43.

8. Boyd JG, Gordon T. A dose-dependent facilitation and inhibition of peripheral nerve regeneration by brain-derived neurotrophic factor. Eur J Neurosci 2002;15:613-26.

9. Yan JG. Transmission electron microscope observation of morbid nerve segments in neurocausalgia. Zhonghua Wai Ke Za Zhi 1990;28:83-4.

10. Bryan DJ, Wang KK, Summerhayes C. Migration of Schwann cells in peripheral-nerve regeneration. J Reconstr Microsurg 1999;15:591-6.

11. Kotulska K, Marcol W, Larysz-Brysz M, et al. Effect of oblique nerve grafting on peripheral nerve regeneration in rats. Microsurgery 2006;26:579-84. 